\title{
Oxidative Dehydrogenation of Ethylbenzene over ZSM-5 Type Chromosilicates in the Presence of $\mathrm{CO}_{2}$
}

\author{
Ebrahim Sadeghi',2, Maryam Saket Oskoui' ${ }^{1}$, Maasoume Khatamian ${ }^{*}$, \\ Abdolhossein H. Ghassemi ${ }^{3}$ \\ ${ }^{1}$ Physical Inorganic Chemistry Research Laboratory, Department of Inorganic Chemistry, Faculty of Chemistry, \\ University of Tabriz, Tabriz, Iran \\ ${ }^{2}$ Department of Chemical Engineering, Faculty of Chemistry, University of Tabriz, Tabriz, Iran \\ ${ }^{3} \mathrm{R} \&$ D Department, Tabriz Petrochemical Company, Tabriz, Iran \\ Email: "khatamianm@yahoo.com
}

Received 16 May 2016; accepted 27 June 2016; published 30 June 2016

Copyright (C) 2016 by authors and Scientific Research Publishing Inc.

This work is licensed under the Creative Commons Attribution International License (CC BY).

http://creativecommons.org/licenses/by/4.0/

c) (†) Open Access

\begin{abstract}
In this work, ZSM-5 type chromosilicate samples as K[Cr]ZSM-5(KCS) and Na[Cr]ZSM-5(NCS) were prepared by hydrothermal method and their catalytic properties were investigated for the oxidative dehydrogenation of ethylbenzene in the presence of $\mathrm{CO}_{2}$ as an oxidant using a fixed-bed stainless steel reactor. The prepared samples were characterized by their morphology (SEM), structural parameters (XRD), and textural parameters (BET). The performance of these catalysts was evaluated in terms of conversion, styrene yield, and selectivity. The $\mathrm{KCS}_{\mathrm{BW}}$ catalyst (potassium chromosilicate before washing with distilled water) afforded the highest styrene yield, $56.19 \%$, with the selectivity of $96.05 \%$ in the presence of $\mathrm{CO}_{2}$ because of the coexistence of potassium ion and $\mathrm{Cr}_{2} \mathrm{O}_{3}$ in its structure and their synergistic effect. The influence of the presence of $\mathrm{Cr}_{2} \mathrm{O}_{3}$ and sodium or potassium ion on the catalytic activity of the chromosilicate samples in the catalytic EB dehydrogenation process was discussed in detail. Moreover, according to the results, the catalytic activity of the chromosilicate samples (CS) in EB dehydrogenation was increased by decreasing the surface area.
\end{abstract}

\section{Keywords}

Chromosilicate, Styrene, Ethylbenzene, Dehydrogenation, Chromium Oxide

\footnotetext{
${ }^{*}$ Corresponding author.
}

How to cite this paper: Sadeghi, E., Oskoui, M.S., Khatamian, M. and Ghassemi, A.H. (2016) Oxidative Dehydrogenation of Ethylbenzene over ZSM-5 Type Chromosilicates in the Presence of $\mathrm{CO}_{2}$. Modern Research in Catalysis, 5, 75-84. 


\section{Introduction}

Styrene (ST) belongs to the most important monomers in petrochemical industry and is mainly used for the synthesis of many polymers [1]-[4]. The commercial production of styrene (ST) is performed by the catalytic dehydrogenation of ethylbenzene (EB), utilizing Fe-K-Cr oxide-based catalysts in the presence of superheated steam as a diluent (reaction I) at high temperatures of $600^{\circ} \mathrm{C}-700^{\circ} \mathrm{C}$ [5].

Recently, the dehydrogenation of EB in the presence of carbon dioxide as a mild oxidant (reaction II) has been extensively investigated [6]-[8]. This new strategy is considered an energy-saving and environmentally friendly process. Carbon dioxide, an unwanted greenhouse gas, is depleted by applying in the reaction. According to the literature, the energy required for the new process using $\mathrm{CO}_{2}$ is $1.9 \times 10^{8}$ cal $\cdot \mathrm{t}^{-1}$, only $13 \%$ of which is for the conventional commercial process using steam [1] [9].

According to Mimura et al., there are two possible reaction pathways for the dehydrogenation of EB in the presence of $\mathrm{CO}_{2}$ [1]. The one-step pathway shown in Equation (1) includes the direct oxidative dehydrogenation of EB with $\mathrm{CO}_{2}$. The two-step pathway shown in Equations (2) and (3) includes the reaction coupling of EB simple dehydrogenation with the reverse water-gas shift (RWGS) [10]. According to the method reported by Mimura, the dehydrogenation of EB over the catalyst in the presence of $\mathrm{CO}_{2}$ was estimated to proceed via $45 \%$ of a one-step pathway and 55\% of a two-step pathway [11].

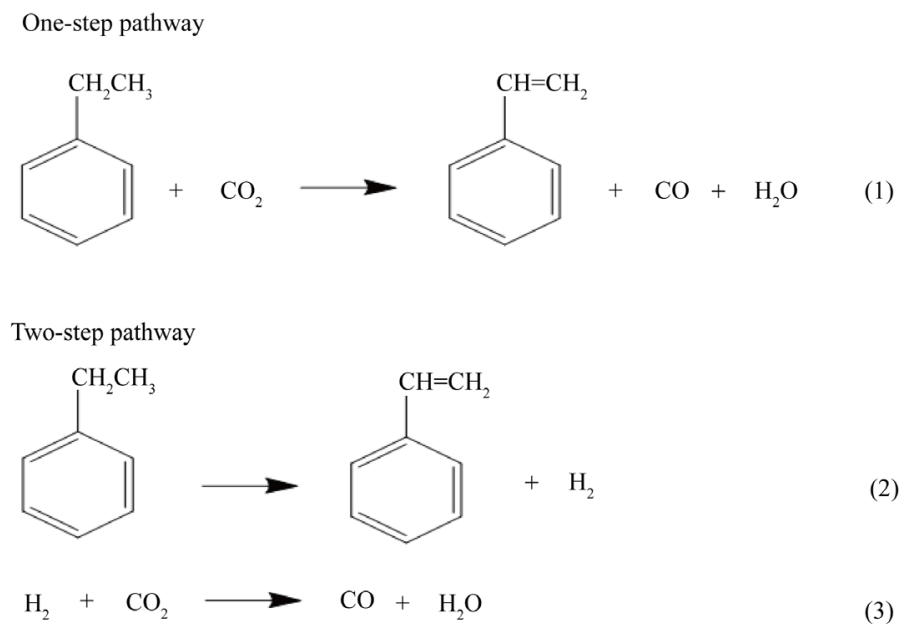

Various catalysts have been used in the dehydrogenation of EB in the presence of $\mathrm{CO}_{2}$, which include ironbased oxides, hydrotalcite-like oxides, zeolites, spinel oxides, active carbon, pillarised clays, active carbon containing promoters (Li, Be, Na, Mg, K, Ca), and carriers for active components (Fe, V, Cr, Cu, Zn, Zr, Ce, La, Ni, Co) [12]-[25]. Among these catalysts, vanadia and chromia are believed to be more active in the dehydrogenation of EB with $\mathrm{CO}_{2}$ [10]. Additionally, according to the fact that support plays a decisive role in disposing the dispersion of the active phase, supported metal or metal oxide catalysis has been extensively increasing both in fundamental and industrial applications [26]. For an instance, it is believed that the catalysts of iron oxide supported on silicon oxides are active and selective in the above reaction [27].

In this contribution, our main purpose was to prepare chromosilicate samples with different alkaline metals (M[Cr]ZSM-5 (M = K, Na)) and study their catalytic activity in the oxidative dehydrogenation of ethylbenezene in the presence of $\mathrm{CO}_{2}$. It is interesting to mention that chromosilicate can be considered the supported chromia in a silicon oxide matrix (as a conventional support). For this purpose, the influence of alkali-metal type (K or $\mathrm{Na}$ ) of chromosilicate structure as well as the amount of chromium oxide on their catalytic performance in the EB dehydrogenation process was investigated.

\section{Experimental}

\subsection{Catalyst Preparation}

2.1.1. Preparing $M[C r] Z S M-5$ (M = K, Na)

$\mathrm{Na}[\mathrm{Cr}] \mathrm{ZSM}-5$ (NCS)and K[Cr]ZSM-5 (KCS) were prepared according to the procedure in our previous work 
[28]. Materials that were used for the preparation of the samples were as follows: silicic acid (Merck), chromium (III) nitrate (Merck), potassium (or sodium) carbonate (Merck), and tetrapropylammonium bromide (TPABr, Merck) (as template). Molar ratios of the synthesized samples were $\mathrm{Si} / \mathrm{Cr}=15, \mathrm{TPABr} / \mathrm{Si}=0.17, \mathrm{H}_{2} \mathrm{O} / \mathrm{Si}=35$, and $\mathrm{K}($ or $\mathrm{Na}) / \mathrm{Si}=2$. In a typical synthesis, at first the solution of silicic acid and sodium (orpotassium or cesium) carbonate in distilled water was prepared and added slowly to the solution of $\mathrm{Cr}\left(\mathrm{NO}_{3}\right)_{3}-9 \mathrm{H}_{2} \mathrm{O}$ and sulfuric acid in water with $\mathrm{pH}=0.5$; then, $\mathrm{pH}$ of the mixture adjusted at about 9 using concentrated sulfuric acid. Then TPABr was added; and the obtained gel was maintained at room temperature for about $4 \mathrm{~h}$ under vigorous stirring. The resulting gel was transferred into Teflon-lined stainless-steel autoclave. Na[Cr]ZSM-5 or K[Cr]ZSM-5 or Cs[Cr]ZSM- 5 was obtained after about $100 \mathrm{~h}$ of hydrothermal treatment of the mixtures at $155^{\circ} \mathrm{C}$. After crystallization, the as-synthesized solids were washed several times with distilled water and dried overnight in an oven at $120^{\circ} \mathrm{C}$. Calcination of the samples was made under air for $5 \mathrm{~h}$ at $550^{\circ} \mathrm{C}$. At this point, the obtained product (MCS) was washed with distilled water in order to remove chromium species. Thus, KCS samples before and after washing, were labeled as $\mathrm{KCS}_{\mathrm{BW}}$ and $\mathrm{KCS}_{\mathrm{AW}}$, respectively. By the same way, NCS samples before and after washing were labeled as $\mathrm{NCS}_{\mathrm{BW}}$ and $\mathrm{NCS}_{\mathrm{AW}}$, respectively.

\subsubsection{Characterization of Catalysts}

The X-ray powder diffraction profiles of the samples were examined by means of a STOE X-ray diffractometer system (Version: PKS-2.01) equipped with $\mathrm{Cu} K \alpha$ radiation $(\lambda=1.540598 \AA$ ). The applied voltage and current were $40 \mathrm{kV}$ and $40 \mathrm{~mA}$, respectively. The samples were scanned from $2 \theta$ of $4^{\circ}-70^{\circ}$ with the step size of $0.06^{\circ}$ and counting time of $1.0 \mathrm{sec} / \mathrm{step}$.

Scanning electron microscopy (SEM) and dispersive analysis (EDX) were performed to characterize the morphology and surface composition. The analyses were carried out using Philips XL-30 system equipped with an EDX detector on the samples coated with a thin layer of gold.

\subsection{Apparatus and Procedure}

Figure 1 shows a schematic diagram of the used experimental setup for the dehydrogenation of EB process. The dehydrogenation experiments were carried out on catalysts, pelletized, crushed, and sieved at about $0.5-1 \mathrm{~mm}$ diameter under atmospheric pressure in a continuous-flow type reactor made of a stainless steel tube ( $4.3 \mathrm{~mm}$ i.d. and $500 \mathrm{~mm}$ length) placed in an electrically heated furnace. Since the low reactor pressure gradients of the catalyst bed improves the yield and selectivity of ST production, in the industry, it is better to use the catalyst in the form of pellet or extrudate. Thus, our samples were supplied in the form of cylindrical pellets of $1 \mathrm{~mm}$ diameter

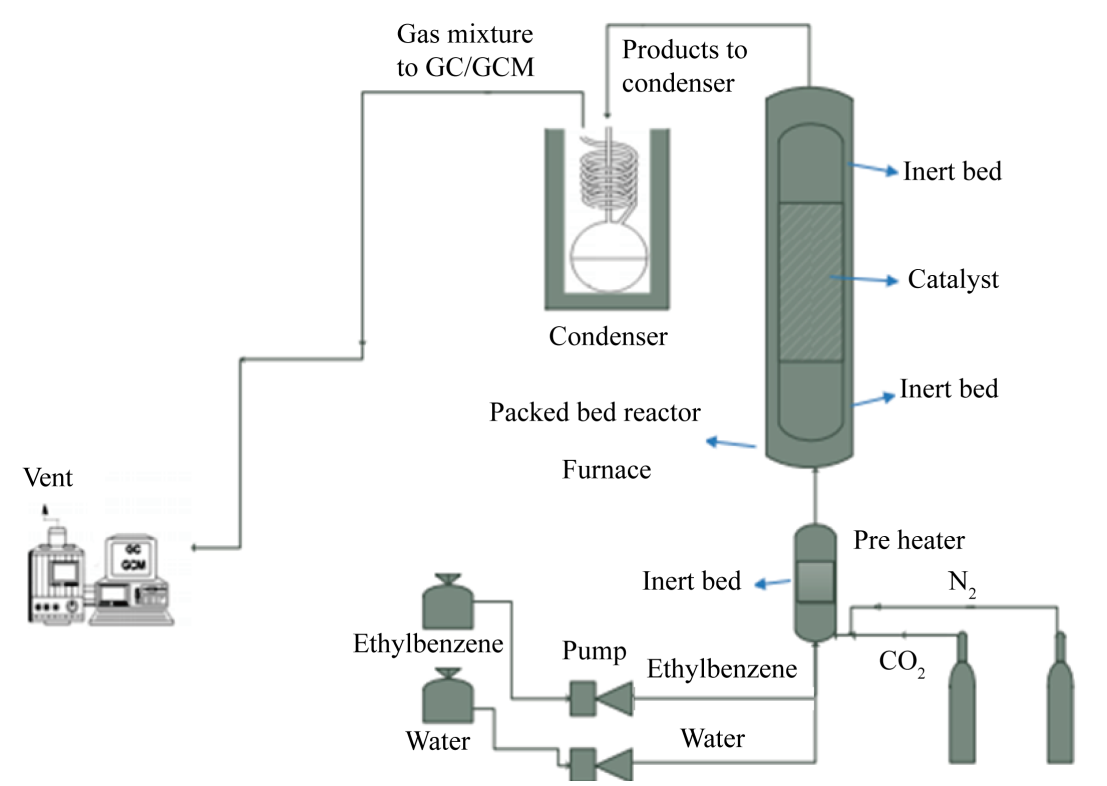

Figure 1. Schematic diagram of the experimental setup used for dehydrogenation of ethylbenzene to styrene. 
and $0.7 \mathrm{~cm}$ length. Prior to the dehydrogenation of EB, the reactor was loaded with $2.0 \mathrm{~g}$ of the catalyst with the support of quartz beads. The reaction was performed at $973 \mathrm{~K}$ for $4 \mathrm{~h}$. Before EB was introduced into the reactor, the catalyst was pretreated under the flow of $\mathrm{N}_{2}\left(100 \mathrm{ml} \cdot \mathrm{min}^{-1}\right)$ from room temperature to $973 \mathrm{~K}$ at the heating rate of $3^{\circ} \mathrm{C} / \mathrm{min}$ and maintained at this temperature for $30 \mathrm{~min}$. A mixture of $\mathrm{EB}$ and $\mathrm{CO}_{2}\left(\mathrm{CO}_{2}\right.$ : $\mathrm{EB}$ molar ratio $\leq 3$ ) was introduced into the reactor using a pump with the feed rate of $36.64 \mathrm{ml} \cdot \mathrm{min}^{-1}$. The outlet stream from the reactor was passed through a condenser equipped with the ice bath for GC analysis. The obtained products were analyzed by a Varian 3800 CX gas chromatograph apparatus using a flame inductivity detector (FID). Helium was used as the carrier gas, the injection temperature was $180^{\circ} \mathrm{C}$, and the samples were injected into the split injection mode. For each measurement, at least three repeated injections were taken, which obtained reproducible results. ST, toluene, and benzene were the main desired products. The peak area normalization method was used for the quantitative analysis of the products. Benzene was the standard sample (sensitivity factor was set at 1).

$$
\begin{gathered}
\text { Ethylbenzene conversion }=1-\frac{\text { ethylebenzene }_{\text {out }}}{(\text { ethylebenzene }+ \text { styrene }+ \text { toluene }+ \text { benzene })_{\text {out }}} \\
\text { Styrene selectivity }=\frac{\text { styrene }_{\text {out }}}{(\text { styrene }+ \text { toluene }+ \text { benzene })_{\text {out }}}
\end{gathered}
$$

where ethylbenzene out or styrene out stands for the amount of ethylbenzene or styrene in the products. Moreover, the styrene yield is calculated using the output data of GC analysis.

\section{Result and Discussion}

\subsection{XRD Analysis}

The XRD patterns of the prepared chromosilicate samples are given in Figure 2. For comparative purposes, the chromosilicate samples (CS) after and before washing with distilled water were included in this Figure (Figure 2).

As shown in Figure 2, XRD patterns of the synthesized chromosilicate samples (Na[Cr]ZSM-5 (NCS) and $\mathrm{K}[\mathrm{Cr}] Z S M-5$ (KCS)) was in good agreement with the XRD pattern of ZSM-5 zeolite with orthorhombic sym-

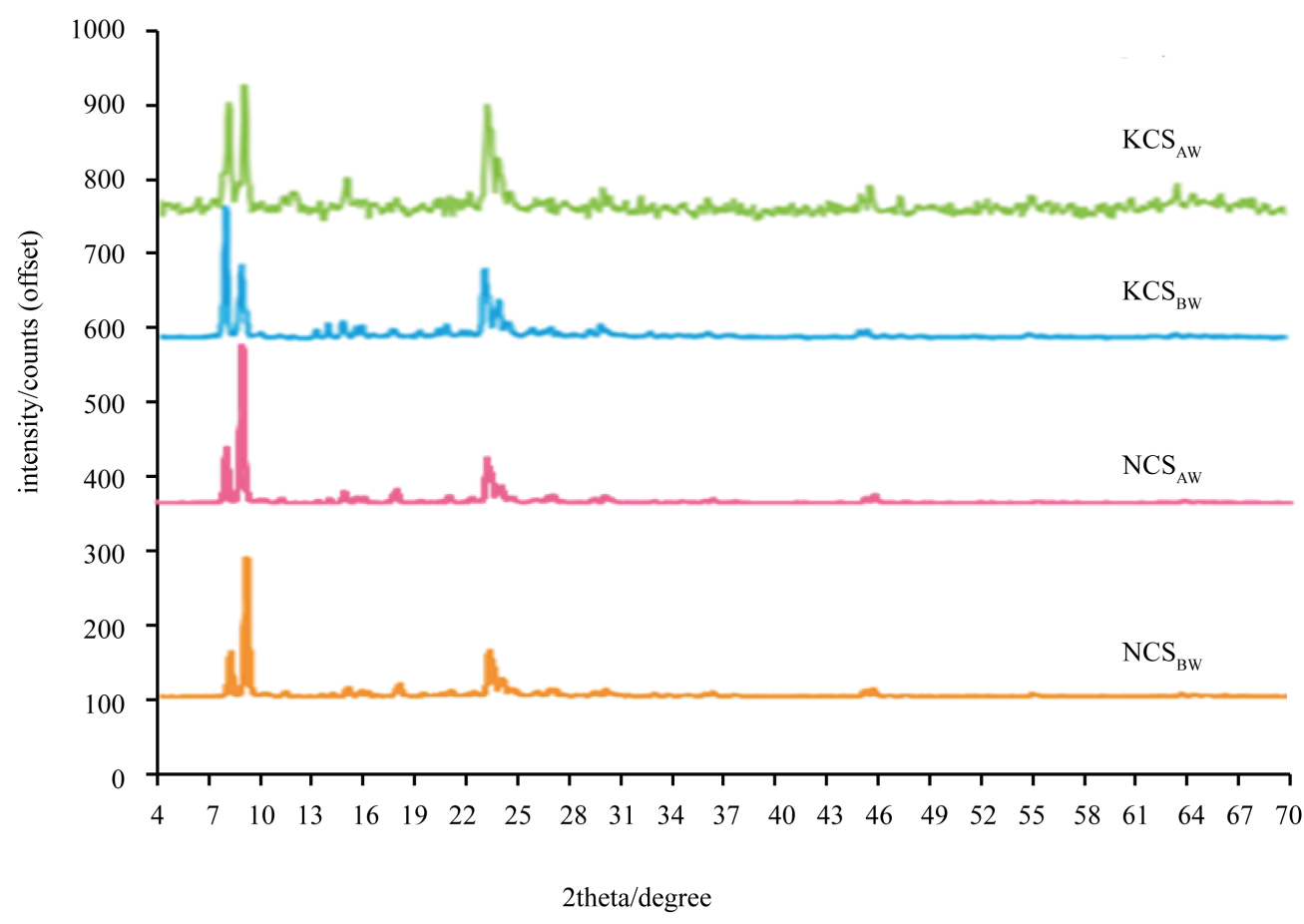

Figure 2. XRD patterns of the prepared samples. 
metry in the literature [27], which was characterized by peaks at $2 \theta=7.94,8.86,23.10,23.9$, and 24.45, representing (011), (200), (051), (033), and (313) planes of crystal structure, respectively. Additionally, an extremely small peak was observed at 31.68 due to the crystalline $\mathrm{CrO}_{3}$ phase in NCS sample which was calcined in air. It is noteworthy that this small peak disappeared after washing the mentioned sample with distilled water. Moreover, there were also some differences in the intensities of some lines between these samples and ZSM-5 zeolite (prepared in our laboratory [29]). These variations confirmed the incorporation of chromium in the structure [28].

\subsection{BET Surface Analysis}

BET surface areas $\left(\mathrm{S}_{\mathrm{BET}}\right)$ of $\mathrm{KCS}_{\mathrm{AW}}, \mathrm{KCS}_{\mathrm{BW}}, \mathrm{NCS}_{\mathrm{AW}}$, and $\mathrm{NCS}_{\mathrm{BW}}$ samples are presented in Table 1. As can be observed, NCS samples, compared with KCS samples, had a relatively higher surface area. Between the NCS or KCS samples, the sample after washing with distilled water $\left(\mathrm{NCS}_{\mathrm{AW}}\right.$ or $\left.\mathrm{KCS}_{\mathrm{AW}}\right)$ has higher surface area than the one before washing, which can be related to the removal of significant amounts of $\mathrm{Cr}_{2} \mathrm{O}_{3}$ after washing with distilled water.

\subsection{Morphology Studies}

SEM images of KCS and NCS samples, before and also after washing with water, are shown in Figure 3. It can be distinguished that NCS appears in the form of cubic particles; its particle size ranged from 7 to $8 \mu \mathrm{m}$, whereas KCS had well-formed and fairly uniform coffin-type crystals of relatively large sizes (about $20-21 \mu \mathrm{m}$ ). The SEM images of KCS and NCS samples revealed the proper growth of crystal grains. However, a few smaller grains with low crystallinity or even amorphous still existed, which were perhaps due to the incomplete crystallization of some particles or could be assigned to $\mathrm{CrO}_{3}$ particles. In order to understand the origin of these particles, we decided to perform SEM analysis for the mentioned samples after washing with distilled water. The aim was to understand the nature of these particles. According to Figure 3, it can be inferred that washing the samples with water resulted in removing a large amount of the grains and a small ratio of them was left. So, a large amount of these particles could be related to $\mathrm{CrO}_{3}$ particles and the remaining particles were the ones which could not completely perform crystallization process. This result is in agreement with EDX analysis (Table 2).

\subsection{Catalytic Performance of the Prepared Samples}

A great deal of research has been conducted for the development of catalysts with improved dehydrogenation activity for the new process, since the commercial K-promoted iron oxide catalysts do not work effectively for EB dehydrogenation in the presence of $\mathrm{CO}_{2}$. For this purpose, a variety of metal oxide catalysts, such as iron oxide [30] [31], vanadia [8] [32], chromia [7] [33], ceria [7], and zirconia [34] has been studied by many researchers.

On the other hand, it should be mentioned that silica- and alumina-supported chromium oxides are industrially used for the productions of lower alkenes such as ethene, propene, and isobutene through the dehydrogenation of the corresponding alkanes [35] [36]. Carbon dioxide is believed to enhance the dehydrogenation of ethane [8]

Table 1. BET surface area and catalytic activity of the prepared catalysts in EB dehydrogenation at $600^{\circ} \mathrm{C}$ and $\mathrm{CO}_{2}$ flow of $36.64 \mathrm{ml} \cdot \mathrm{min}^{-1}$.

\begin{tabular}{|c|c|c|c|c|c|c|c|}
\hline Components & $\mathrm{CO}_{2}\left(\mathrm{ml} \cdot \mathrm{min}^{-1}\right)$ & $\mathrm{S}_{\mathrm{BET}}\left(\mathrm{m}^{2} / \mathrm{g}\right)$ & X [\%] & Bz [\%] & Tol [\%] & $\mathrm{S}[\%]$ & $\begin{array}{c}\text { EB conversion } \\
{[\%]}\end{array}$ \\
\hline IC & 36.64 & 4.64 & 41.09 & 11.62 & 9.94 & 65.58 & 62.65 \\
\hline $\mathrm{KCS}_{\mathrm{AW}}$ & 36.64 & 307.59 & 40.52 & 3.5 & 2.08 & 87.80 & 46.15 \\
\hline $\mathrm{KCS}_{\mathrm{BW}}$ & 36.64 & 294.02 & 56.19 & 1.07 & 1.24 & 96.05 & 58.5 \\
\hline $\mathrm{NCS}_{\mathrm{AW}}$ & 36.64 & 316.62 & 44.81 & 2.24 & 3.32 & 88.96 & 50.37 \\
\hline $\mathrm{NCS}_{\mathrm{BW}}$ & 36.64 & 307.74 & 46.38 & 1.24 & 1.87 & 93.72 & 49.49 \\
\hline
\end{tabular}

$\mathrm{X}=$ Styrene yield, Bz = Benzene, Tol = Toluene, $\mathrm{S}=$ Styrene selectivity, EB = Ethylbenzene. 

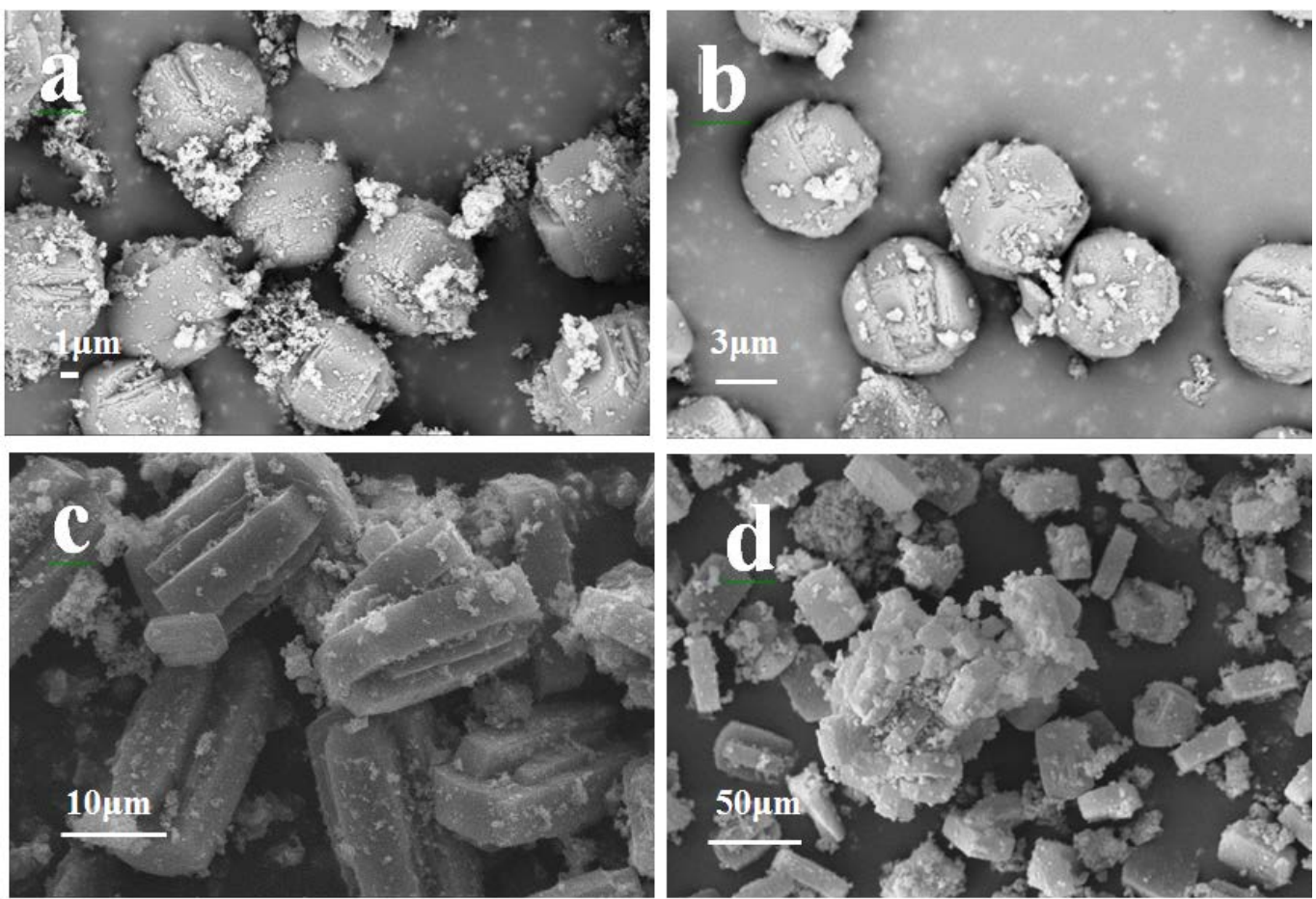

Figure 3. SEM images of $\mathrm{NCS}_{\mathrm{BW}}(\mathrm{a}), \mathrm{NCS}_{\mathrm{AW}}(\mathrm{b}), \mathrm{KCS}_{\mathrm{BW}}$ (c) and $\mathrm{KCS}_{\mathrm{BW}}(\mathrm{d})$.

Table 2. EDX information of the samples.

\begin{tabular}{lccccc}
\hline & \multicolumn{5}{c|}{ Elements } \\
\cline { 2 - 6 } Sample & Na (wt\%) & K (wt\%) & Si (wt\%) & $\mathrm{Cr}(\mathrm{wt} \%)$ & $\mathrm{O}(\mathrm{wt} \%)$ \\
\hline $\mathrm{NCS}_{\mathrm{BW}}$ & 2 & - & 35 & 7 & 56 \\
$\mathrm{NCS}_{\mathrm{AW}}$ & 2 & - & 37 & 3 & 58 \\
$\mathrm{KCS}_{\mathrm{BW}}$ & - & 1 & 36 & 6 & 57 \\
$\mathrm{KCS}_{\mathrm{AW}}$ & - & 1 & 38 & 2 & 59
\end{tabular}

[37] [38], propane [4] [24] [39]-[41], or isobutene [34] over supported chromium oxide. The reduction-oxidation property and the appropriate dispersion of chromium species on the support are important in these catalytic reactions [18] [42]. Aiming to find alternative catalysts for this reaction, we utilized the mentioned methods for improving the activity of Fe-K commercial catalyst in the dehydrogenation of EB process in the presence of $\mathrm{CO}_{2}$. In this trend, some new catalysts had to be designed on the basis of the commercial catalyst for the purpose of performing the mentioned process with proper efficiency. Chromosilicate (which can be considered the supported chromium oxide in the silicon oxide matrix) can be a good candidate. Furthermore, for the purpose of understanding the roles of chromium oxide and alkali-metal type ( $\mathrm{K}$ or $\mathrm{Na}$ ) of chromosilicate structure, in determining the catalytic activity of different types of chromosilicate, various chromosilicate samples were prepared.

Table 1 and Figure 4 present the results of the dehydrogenation of EB with $\mathrm{CO}_{2}$ over the various chromosilicate catalysts and a Fe-K commercial catalyst for comparison. We found that, in the presence of the new catalysts, EB was predominantly converted into ST via an oxidative manner and ST selectivity was improved at the cost of a decrease in conversion [43]. According to the results (Table 1, Figure 4), the MCS-based catalysts can be ordered in terms of their selectivity toward ST production as follows:

$$
\mathrm{KCS}_{\mathrm{BW}}>\mathrm{NCS}_{\mathrm{BW}}>\mathrm{NCS}_{\mathrm{AW}}>\mathrm{KCS}_{\mathrm{AW}}
$$

This order can be related to the important role of potassium ion as an effective promoter as well as that of 


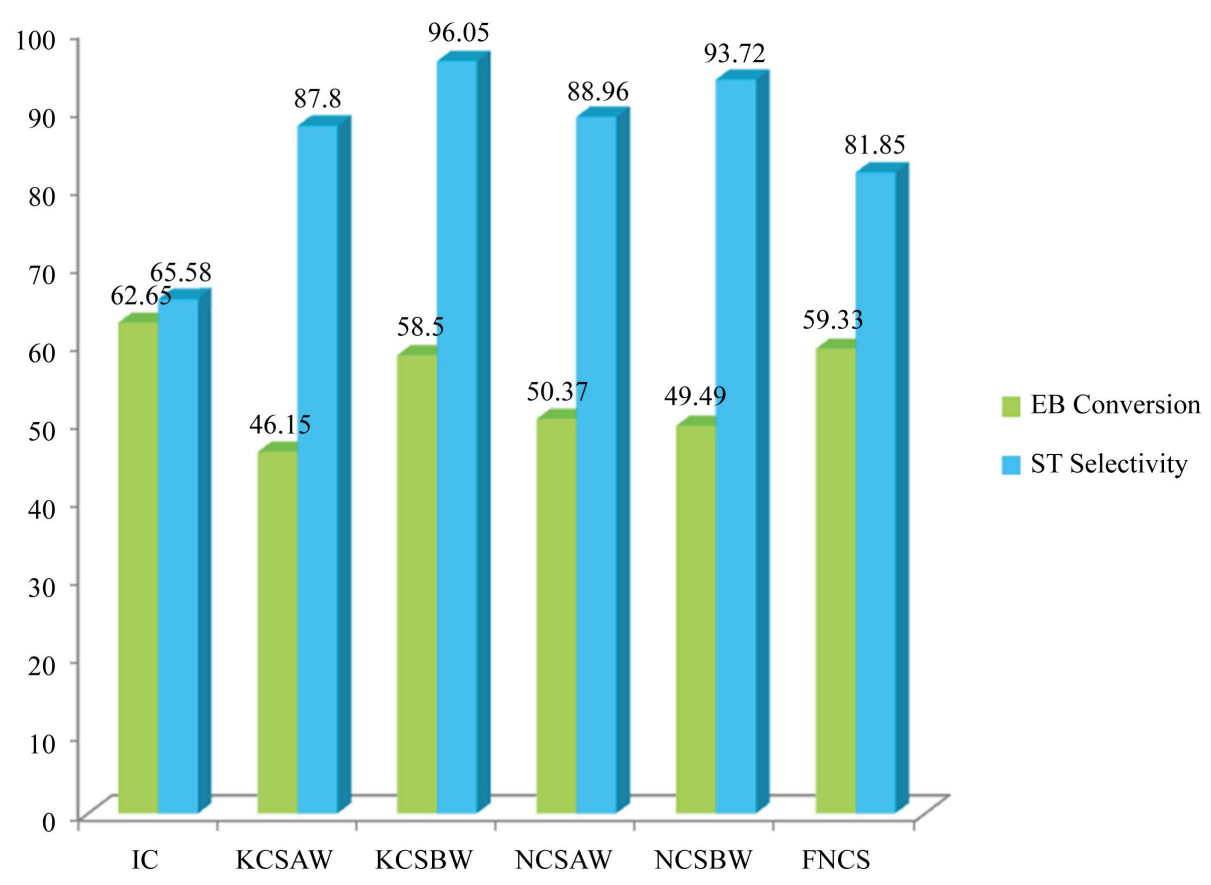

Figure 4. The performance of various chromosilicate samples (M[Cr]ZSM-5) in ethylbenzene dehydrogenation reaction in the presence of $\mathrm{CO}_{2}$ at $600^{\circ} \mathrm{C}$.

$\mathrm{Cr}_{2} \mathrm{O}_{3}$ as a proper co-promoter in these catalysts. In the case of $\mathrm{KCS}_{\mathrm{BW}}$ sample, both potassium ion and $\mathrm{Cr}_{2} \mathrm{O}_{3}$ coexisted in this catalyst and the high conversion and selectivity were the result of the mentioned species. By removing the significant amounts of $\mathrm{Cr}_{2} \mathrm{O}_{3}$, via washing, the obtained sample $\left(\mathrm{KCS}_{\mathrm{AW}}\right)$ had lower selectivity even compared with its sodium analogous $\left(\mathrm{NCS}_{\mathrm{AW}}\right)$. This result can highlight the importance of the synergic effect of potassium ion and $\mathrm{Cr}_{2} \mathrm{O}_{3}$ for improving the catalytic activity of the sample. The presence of sodium instead of potassium as the alkali metal ion in the structure of chromosilicate can slightly enhance the ST selectivity of the $\mathrm{CS}_{\mathrm{AW}}$ samples (chromosilicate samples after washing with distilled water and removing a significant amount of $\mathrm{Cr}_{2} \mathrm{O}_{3}$ ). This trend confirmed that the synergic effect of potassium ion and $\mathrm{Cr}_{2} \mathrm{O}_{3}$ for improving the catalytic activity was a little bit more important than that of sodium ion and $\mathrm{Cr}_{2} \mathrm{O}_{3}$.

Moreover, regarding the results of Table 1, it is noteworthy that the catalytic activity of the chromosilicate samples in EB dehydrogenation increased by decreasing the surface area.

\section{Conclusion}

The catalytic performance of chromosilicate catalysts as M[Cr]ZSM-5 (MCS) (M = K, Na) was investigated in the oxidative dehydrogenation of EB through $\mathrm{CO}_{2}$. The $\mathrm{KCS}_{\mathrm{BW}}$ catalyst (potassium chromosilicate before washing with distilled water) afforded the highest ST yield, 56.19\%, with the selectivity of $96.05 \%$ in the presence of $\mathrm{CO}_{2}$ because of the coexistance of potassium ion and $\mathrm{Cr}_{2} \mathrm{O}_{3}$ in its structure. By removing the significant amounts of $\mathrm{Cr}_{2} \mathrm{O}_{3}$, via washing with distilled water, the obtained sample $\left(\mathrm{KCS}_{\mathrm{Aw}}\right)$ had lower selectivity, even in comparison with its sodium analogous $\left(\mathrm{NCS}_{\mathrm{AW}}\right)$. This result could highlight the importance of the synergic effect of potassium ion and $\mathrm{Cr}_{2} \mathrm{O}_{3}$ for improving the catalytic activity of the sample. This trend confirmed that the synergic effect of potassium ion and $\mathrm{Cr}_{2} \mathrm{O}_{3}$ for improving the catalytic activity was a little bit more important than that of sodium ion and $\mathrm{Cr}_{2} \mathrm{O}_{3}$. Moreover, regarding the results, it is noteworthy that the catalytic activity of the chromosilicate samples (CS) in EB dehydrogenation is increased by decreasing the surface area.

\section{Acknowledgements}

The authors would like to thank the University of Tabriz and Iranian Nanotechnology Initiative Council for the financial support of this project. 


\section{References}

[1] Mimura, N., Takahara, I., Saito, M., Hattori, T., Ohkuma, K. and Ando, M. (1998) Dehydrogenation of Ethylbenzene over Iron Oxide-Based Catalyst in the Presence of Carbon Dioxide. Catalysis Today, 45, 61-64. http://dx.doi.org/10.1016/S0920-5861(98)00246-6

[2] Mross, W. (1983) Alkali Doping in Heterogeneous Catalysis. Catalysis Reviews Science and Engineering, 25, $591-637$. http://dx.doi.org/10.1080/01614948308078057

[3] Sato, S., Ohhara, M., Sodesawa, T. and Nozaki, F. (1988) Combination of Ethylbenzene Dehydrogenation and Carbon Dioxide Shift-Reaction over a Sodium Oxide/Alumina Catalyst. Applied Catalysis, 37, 207-215. http://dx.doi.org/10.1016/S0166-9834(00)80761-7

[4] Sugino, M.-O., Shimada, H., Turuda, T., Miura, H., Ikenaga, N. and Suzuki, T. (1995) Oxidative Dehydrogenation of Ethylbenzene with Carbon Dioxide. Applied Catalysis A: General, 121, 125-137. http://dx.doi.org/10.1016/0926-860X(95)85015-5

[5] Sun, A., Qin, Z., Chen, S. and Wang, J. (2004) Role of Carbon Dioxide in the Ethylbenzene Dehydrogenation Coupled with Reverse Water-Gas Shift. Journal of Molecular Catalysis A: Chemical, 210, 189-195. http://dx.doi.org/10.1016/j.molcata.2003.09.016

[6] Badstube, T., Papp, H., Dziembaj, R. and Kustrowski, P. (2000) Screening of Catalysts in the Oxidative Dehydrogenation of Ethylbenzene with Carbon Dioxide. Applied Catalysis A: General, 204, 153-165. http://dx.doi.org/10.1016/S0926-860X(00)00514-7

[7] Ikenaga, N.-O., Tsuruda, T., Senma, K., Yamaguchi, T., Sakurai, Y. and Suzuki, T. (2000) Dehydrogenation of Ethylbenzene with Carbon Dioxide Using Activated Carbon-Supported Catalysts. Industrial \& Engineering Chemistry Research, 39, 1228-1234. http://dx.doi.org/10.1021/ie990426q

[8] Sakurai, Y., Suzaki, T., Nakagawa, K., Ikenaga, N.-O., Aota, H. and Suzuki, T. (2002) Dehydrogenation of Ethylbenzene over Vanadium Oxide-Loaded MgO Catalyst: Promoting Effect of Carbon Dioxide. Journal of Catalysis, 209, 1624. http://dx.doi.org/10.1006/jcat.2002.3593

[9] de Morais Batista, A.H., Ramos, F.S., Braga, T.P., Lima, C.L., De Sousa, F.F., Barros, E.B., Josue Filho, M., De Oliveira, A.S., De Sousa, J.R. and Valentini, A. (2010) Mesoporous $\mathrm{MAl}_{2} \mathrm{O}_{4}(\mathrm{M}=\mathrm{Cu}, \mathrm{Ni}$, Fe or Mg) Spinels: Characterisation and Application in the Catalytic Dehydrogenation of Ethylbenzene in the Presence of $\mathrm{CO}_{2}$. Applied Catalysis A: General, 382, 148-157. http://dx.doi.org/10.1016/j.apcata.2010.04.027

[10] Qiao, Y., Miao, C., Yue, Y., Xie, Z., Yang, W., Hua, W. and Gao, Z. (2009) Vanadium Oxide Supported on Mesoporous MCM-41 as New Catalysts for Dehydrogenation of Ethylbenzene with $\mathrm{CO}_{2}$. Microporous and Mesoporous Materials, 119, 150-157. http://dx.doi.org/10.1016/j.micromeso.2008.10.010

[11] Mimura, N. and Saito, M. (2000) Dehydrogenation of Ethylbenzene to Styrene in the Presence of $\mathrm{CO}_{2}$. Applied Organometallic Chemistry, 14, 773-777. http://dx.doi.org/10.1002/1099-0739(200012)14:12<773::AID-AOC73>3.0.CO;2-I

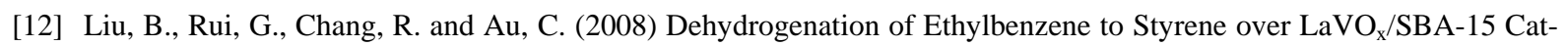
alysts in the Presence of Carbon Dioxide. Applied Catalysis A: General, 335, 88-94. http://dx.doi.org/10.1016/j.apcata.2007.11.013

[13] Li, H., Yue, Y., Miao, C., Xie, Z., Hua, W. and Gao, Z. (2007) Dehydrogenation of Ethylbenzene and Propane over $\mathrm{Ga}_{2} \mathrm{O}_{3}-\mathrm{ZrO}_{2}$ Catalysts in the Presence of $\mathrm{CO}_{2}$. Catalysis Communications, 8, 1317-1322. http://dx.doi.org/10.1016/j.catcom.2006.11.034

[14] de Morais Batista, A.H., de Sousa, F.F., Honorato, S.B., Ayala, A.P., Josue Filho, M., de Sousa, F.W., Pinheiro, A.N., de Araujo, J., Nascimento, R.F. and Valentini, A. (2010) Ethylbenzene to Chemicals: Catalytic Conversion of Ethylbenzene into Styrene over Metal-Containing MCM-41. Journal of Molecular Catalysis A: Chemical, 315, 86-98. http://dx.doi.org/10.1016/j.molcata.2009.09.006

[15] Li, X.-H., Li, W.-Y. and Xie, K.-C. (2005) Supported Vanadia Catalysts for Dehydrogenation of Ethylbenzene with $\mathrm{CO}_{2}$. Catalysis Letters, 105, 223-227. http://dx.doi.org/10.1007/s10562-005-8694-5

[16] Burri, D.R., Choi, K.-M., Han, D.-S., Jiang, N., Burri, A. and Park, S.-E. (2008) Oxidative Dehydrogenation of Ethylbenzene to Styrene with $\mathrm{CO}_{2}$ over $\mathrm{SnO}_{2}-\mathrm{ZrO}_{2}$ Mixed Oxide Nanocomposite Catalysts. Catalysis Today, 131, 173-178. http://dx.doi.org/10.1016/j.cattod.2007.10.031

[17] Freire, R.M., de Sousa, F.F., Pinheiro, A.L., Longhinotti, E., Mendes Filho, J., Oliveira, A.C., Paulo de Tarso, C.F., Ayala, A.P. and Oliveira, A.C. (2009) Studies of Catalytic Activity and Coke Deactivation of Spinel Oxides during Ethylbenzene Dehydrogenation. Applied Catalysis A: General, 359, 165-179. http://dx.doi.org/10.1016/j.apcata.2009.02.036

[18] Sun, A., Qin, Z. and Wang, J. (2002) Reaction Coupling of Ethylbenzene Dehydrogenation with Water-Gas Shif. Applied Catalysis A: General, 234, 179-189. http://dx.doi.org/10.1016/S0926-860X(02)00222-3 
[19] Ohishi, Y., Kawabata, T., Shishido, T., Takaki, K., Zhang, Q., Wang, Y., Nomura, K. and Takehira, K. (2005) Mg-Fe-Al Mixed Oxides with Mesoporous Properties Prepared from Hydrotalcite as Precursors: Catalytic Behavior in Ethylbenzene Dehydrogenatio. Applied Catalysis A: General, 288, 220-231.

http://dx.doi.org/10.1016/j.apcata.2005.04.033

[20] Kuśtrowski, P., Rafalska-Łasocha, A., Majda, D., Tomaszewska, D. and Dziembaj, R. (2001) Preparation and Characterization of New Mg-Fe-Al Oxide Catalyst Precursors for Dehydrogenation of Ethylbenzene in the Presence of Carbon Dioxid. Solid State Ionics, 141, 237-242. http://dx.doi.org/10.1016/S0167-2738(01)00752-4

[21] Oganowski, W., Hanuza, J. and Kepiński, L. (1998) Catalytic Properties of $\mathrm{Mg}_{3}\left(\mathrm{VO}_{4}\right)_{2}$-MgO System in Oxidative Dehydrogenation of Ethylbenzen. Applied Catalysis A: General, 171, 145-154. http://dx.doi.org/10.1016/S0926-860X(98)00085-4

[22] Serafin, I., Kotarba, A., Grzywa, M., Sojka, Z., Bińczycka, H. and Kuśtrowski, P. (2006) Quenching of Potassium Loss from Styrene Catalyst: Effect of $\mathrm{Cr}$ Doping on Stabilization of the $\mathrm{K}_{2} \mathrm{Fe}_{22} \mathrm{O}_{34}$ Active Phas. Journal of Catalysis, 239, 137-144. http://dx.doi.org/10.1016/j.jcat.2006.01.026

[23] Areán, C.O. Mentruit, M.P., López, A.L. and Parra, J. (2001) High Surface Area Nickel Aluminate Spinels Prepared by a Sol-Gel Method. Colloids and Surfaces A: Physicochemical and Engineering Aspects, 180, 253-258. http://dx.doi.org/10.1016/S0927-7757(00)00590-2

[24] Ye, X., Ma, N., Hua, W., Yue, Y., Miao, C., Xie, Z. and Gao, Z. (2004) Dehydrogenation of Ethylbenzene in the Presence of $\mathrm{CO}_{2}$ over Catalysts Prepared from Hydrotalcite-Like Precursor. Journal of Molecular Catalysis A: Chemical, 217, 103-108. http://dx.doi.org/10.1016/j.molcata.2004.02.024

[25] Li. Z. and Shanks, B.H. (2009) Stability and Phase Transitions of Potassium-Promoted Iron Oxide in Various Gas Phase Environment. Applied Catalysis A: General, 354, 50-56. http://dx.doi.org/10.1016/j.apcata.2008.11.007

[26] Maity, S., Rana, M., Srinivas, B., Bej, S., Dhar, G.M. and Rao, T.P. (2000) Characterization and Evaluation of $\mathrm{ZrO}_{2}$ Supported Hydrotreating Catalyst. Journal of Molecular Catalysis A: Chemical, 153, 121-127. http://dx.doi.org/10.1016/S1381-1169(99)00311-8

[27] Oliveira, A.C., Fierro, J.L., Valentini, A., Nobre, P.S.S. and do Carmo Rangel, M. (2003) Non-Toxic Fe-Based Catalysts for Styrene Synthesis: The Effect of Salt Precursors and Aluminum Promoter on the Catalytic Propertie. Catalysis Today, 85, 49-57. http://dx.doi.org/10.1016/S0920-5861(03)00193-7

[28] Khatamian, M., Oskoui, M.S. and Darbandi, M. (2013) Synthesis and Characterization of Aluminium-Free ZSM-5 Type Chromosilicates in Different Alkaline Systems and Investigation of Their Pore Structure. Microporous and Mesoporous Materials, 182, 50-61. http://dx.doi.org/10.1016/j.micromeso.2013.07.011

[29] Khatamian, M. and Irani, M. (2009) Preparation and Characterization of Nanosized ZSM-5 Zeolite Using Kaolin and Investigation of Kaolin Content, Crystallization Time and Temperature Changes on the Size and Crystallinity of Product. Journal of the Iranian Chemical Society, 6, 187-194. http://dx.doi.org/10.1007/BF03246519

[30] Saito, M., Kimura, H., Mimura, N., Wu, J. and Murata, K. (2003) Dehydrogenation of Ethylbenzene in the Presence of $\mathrm{CO}_{2}$ over an Alumina-Supported iron Oxide Catalys. Applied Catalysis A: General, 239, 71-77. http://dx.doi.org/10.1016/S0926-860X(02)00376-9

[31] Chen, S., Sun, A., Qin, Z. and Wang, J. (2003) Reaction Coupling of Diethylbenzene Dehydrogenation with Water-Gas Shift over Alumina-Supported Iron Oxide Catalyst. Catalysis Communications, 4, 441-447. http://dx.doi.org/10.1016/S1566-7367(03)00110-9

[32] Vislovskiy, V.P., Chang, J.-S., Park, M.-S. and Park, S.-E. (2002) Ethylbenzene into Styrene with Carbon Dioxide over Modified Vanadia-Alumina Catalyst. Catalysis Communications, 3, 227-231. http://dx.doi.org/10.1016/S1566-7367(02)00105-X

[33] Ye, X., Yue, Y., Miao, C., Xie, Z., Hua, W. and Gao, Z. (2005) Effect of Modifiers on the Activity of a $\mathrm{Cr}_{2} \mathrm{O}_{3} / \mathrm{Al}_{2} \mathrm{O}_{3}$ Catalyst in the Dehydrogenation of Ethylbenzene with $\mathrm{CO}_{2}$. Green Chemistry, 7, 524-528. http://dx.doi.org/10.1039/b505781g

[34] Park, J.-N., Noh, J., Chang, J.-S. and Park, S.-E. (2000) Ethylbenzene to Styrene in the Presence of Carbon Dioxide over Zirconi. Catalysis letters, 65, 75-78. http://dx.doi.org/10.1023/A:1019021422534

[35] Trong-On. D., Ungureanu. A. and Kaliaguine, S. (2003) TS-1 Coated Mesocellular Titano-Silica foams as New Catalysts for Oxidation of Bulky Molecule. Physical Chemistry Chemical Physics, 5, 3534-3538. http://dx.doi.org/10.1039/b304834a

[36] Solsona. B., Nieto. J.M.L. and Díaz, U. (2006) Siliceous ITQ-6: A New Support for Vanadia in the Oxidative Dehydrogenation of Propan. Microporous and Mesoporous Materials, 94, 339-347. http://dx.doi.org/10.1016/j.micromeso.2006.04.007

[37] Chen. S., Qin. Z., Xu. X. and Wang. J. (2006) Structure and Properties of the Alumina-Supported Vanadia Catalysts for Ethylbenzene Dehydrogenation in the Presence of Carbon Dioxid. Applied Catalysis A: General, 302, 185-192. 
http://dx.doi.org/10.1016/j.apcata.2006.01.003

[38] Rao, K.N., Reddy, B.M., Abhishek, B., Seo, Y.-H., Jiang, N. and Park, S.-E. (2009) Effect of Ceria on the Structure and Catalytic Activity of $\mathrm{V}_{2} \mathrm{O}_{5} / \mathrm{TiO}_{2}-\mathrm{ZrO}_{2}$ for Oxidehydrogenation of Ethylbenzene to Styrene Utilizing $\mathrm{CO}_{2}$ as $\mathrm{Soft}$ Oxidan. Applied Catalysis B: Environmental, 91, 649-656. http://dx.doi.org/10.1016/j.apcatb.2009.07.003

[39] Chang. J.-S., Vislovskiy. V.P., Park. M.-S., Yoo. J.S. and Park. S.-E. (2003) Utilization of Carbon Dioxide as Soft Oxidant in the Dehydrogenation of Ethylbenzene over Supported Vanadium-Antimony Oxide Catalyst. Green Chemistry, 5, 587-590. http://dx.doi.org/10.1039/B304825J

[40] Liu. Y.-M., Feng. W.-L., Li. T.-C., He. H.-Y., Dai. W.-L., Huang. W., Cao. Y. and Fan, K.-N. (2006) Structure and Catalytic Properties of Vanadium Oxide Supported on mesoCellulous Silica Foams (MCF) for the Oxidative Dehydrogenation of Propane to Propylene. Journal of Catalysis, 239, 125-136. http://dx.doi.org/10.1016/j.jcat.2005.12.028

[41] Badstube, T., Papp, H., Kustrowski, P. and Dziembaj, R. (1998) Oxidative Dehydrogenation of Ethylbenzene with Carbon Dioxide on Alkali-Promoted Fe/Active Carbon Catalyst. Catalysis Letters, 55, 169-172. http://dx.doi.org/10.1023/A:1019099332393

[42] Mimura, N. and Saito, M. (1999) Dehydrogenation of Ethylbenzene to Styrene over $\mathrm{Fe}_{2} \mathrm{O}_{3} / \mathrm{Al}_{2} \mathrm{O}_{3}$ Catalysts in the Presence of Carbon Dioxid. Catalysis Letters, 58, 59-62. http://dx.doi.org/10.1023/A:1019049127309

[43] Wang, S. and Zhu, Z. (2004) Catalytic Conversion of Alkanes to Olefins by Carbon Dioxide Oxidative Dehydrogenation A Revie. Energy \& Fuels, 18, 1126-1139. http://dx.doi.org/10.1021/ef0340716

\section{Submit or recommend next manuscript to SCIRP and we will provide best service for you:}

Accepting pre-submission inquiries through Email, Facebook, Linkedin, Twitter, etc A wide selection of journals (inclusive of 9 subjects, more than 200 journals)

Providing a 24-hour high-quality service

User-friendly online submission system

Fair and swift peer-review system

Efficient typesetting and proofreading procedure

Display of the result of downloads and visits, as well as the number of cited articles

Maximum dissemination of your research work

Submit your manuscript at: http://papersubmission.scirp.org/ 